\title{
Empirical Research on Poverty Reduction Effect Based on Factor Analysis
}

\author{
Ping Xiao* \\ Hunan University of Humanities, Science and Technology, Loudi, Hunan, China \\ ${ }^{*}$ Corresponding author
}

\begin{abstract}
This paper quantitatively analyzes the poverty reduction effect in hunan province from three aspects of economic growth, financial support and industrial development. First, use of factor analysis on the independent variables for dimension reduction, extracting a factor for regional development level factor, the region's economic growth is expressed by the regional development level factors, financial support and industry development. Secondly, poverty incidence rate was selected as poverty reduction effect measurement to build an exponential regression model of regional development level and poverty incidence rate. Finally, it is concluded that regional development level has certain effect on poverty reduction in hunan province.
\end{abstract} model

Keywords-poverty reduction effect; factor analysis; index

\section{INTRODUCTION}

30 years of reform and opening up. State for poverty alleviation policy support, whether it is direct capital expenditures and supporting rural production, expenditure for poverty alleviation or through public infrastructure construction, agriculture, forestry and fishing investment indirectly support, will be accompanied by a rapid decline in rural poverty. Based on the data analysis of all counties in China, Park found that poverty alleviation investment increased per capita income year by year [1]. Funding for poverty alleviation is one of the main ways of support groups, or through direct subsidies groups through poverty alleviation project to improve poor, foster poor ability of self development, realize the poor out of poverty. Whether the investment of poverty alleviation fund is fair and reasonable, and whether the efficiency is optimal, will affect the progress of poverty alleviation in poor areas. However, this does not necessarily mean that there is a causal relationship between increased financial support for agriculture and rural poverty reduction. There are many reasons for rural poverty in China. Researchers at home and abroad mainly focus on education, industry, public infrastructure and financial expenditure. It shows that there are many factors leading to a small number of rural poor people.

Under the constraint of specific economic environment and technological level, the rural poverty reduction effect of increasing financial support for agriculture and rural areas presents the law of marginal decline. Indicators influencing agricultural output and its growth include agricultural capital, financial input to support agriculture, agricultural credit and capital accumulation of farmers [2].

Aid-the-poor funds are also affected by regional investment effect, after the reform and opening-up policy, our country of poverty population in absolute scale and relative scale is steadily declining, poverty rate basically stable at a small ratio, meanwhile, is steadily increasing financial poverty alleviation funds, funds at the same time of increasing poverty is more and more difficult. The impact of agricultural investment on poverty reduction is large, but the overall trend is weakening. $\mathrm{Hu}$ shao-yu investigated different ways of financial rural investment to study the optimal investment portfolio, and found that financial education investment had the greatest effect on poverty alleviation. Of all the factors that affect poverty alleviation, the contribution rate to the western region is the largest, followed by the central region and the eastern region. In other words, financial agricultural investment has a significant impact on poverty alleviation in areas with a large number of poor people and a weak foundation. When the regional rural economy reaches a certain level, the poverty alleviation effect of financial agricultural investment gradually weakens [3]. WuYan [6], 2001-2010 provincial panel data regression analysis, the incidence of poverty in rural financial development level of elasticity is negative, China's rural financial development has an obvious effect of poverty reduction; Rural financial development levels in different regions have different effects on the incidence of poverty. The eastern region has the greatest resilience, followed by the western region, and the central region has a weak poverty reduction effect in rural financial development.

Using vector autoregressive model, zhang quanhong conducted an empirical study on the long-term and short-term relationship between China's rural poverty alleviation fund investment and poverty reduction, and the Granger causality. In the short term, the rural poverty alleviation fund has the promotion function to the rural poverty reduction, but the effect is not significant. In the long run, the poverty alleviation fund has restrained the reduction of rural poverty, but there is no Granger causality between the two. The relationship between economic growth and poverty is complex. While reducing the rural poor population, economic growth increases the poverty depth index and poverty intensity index [4].

Hong-bao guo rural studied the relationship between the the rural financial investment and the effect of decreasing poverty, using ordinary differential equation that fiscal agricultural project investment's contribution to poverty 
alleviation, promoting agricultural production can improve not only the agricultural GDP, fiscal investment but also help poverty [5].

Feng-hua zhang [7] used during the period of "August 7th crucial for poverty alleviation" and "rural poverty alleviation and development" in the new world development period of the provincial panel data, using the econometric model of the industrial structure, agricultural production conditions, agriculture, poverty alleviation and development policy and other key intermediate variable by regression analysis, it is concluded that economic growth and income inequality and the conditions of agricultural production has significant impact on the rural poverty reduction.

As for the relationship between economic growth and poverty reduction, scholars have conducted a lot of studies on it. Together, they found that economic growth has no direct impact on poverty reduction. Poverty reduction is affected by changes in income inequality during economic growth [8].

If economic growth does not increase the disposable income of rural residents and their consumption level is not high, the effect of economic growth on poverty reduction will be ineffective. Therefore, this paper selects GDP, disposable income of rural residents and consumption level of rural residents to study the effects of economic growth on poverty reduction.

Countries on poverty reduction support role mainly from two ways: first, through the government's fiscal transfer payment directly to increase the income of farmers, such as poverty alleviation funds expenditure, support rural production expenses, etc.; Second, through the construction of public facilities, agricultural, forestry, animal husbandry and fishery investment indirect support. Therefore, this paper selects the indicators of poverty alleviation fund expenditure, rural production expenditure, agricultural, forestry, animal husbandry and fishery investment to represent the effect of government poverty alleviation support on poverty reduction.

Financial support for agriculture cannot make poverty alleviation sustainable. While relying on the national "blood transfusion", we should pay attention to the function of "hematopoiesis" in poor areas and achieve poverty alleviation through the development of their own industries. In this paper, the indicators of total tourism revenue and total output value of agriculture, forestry, husbandry and fishery are selected to represent the regional industrial development.

\section{VARIABLE SELECTION}

This paper selects the relevant indicators of hunan province from 2005 to 2016. The dependent variable P is the incidence rate of rural poverty. The independent variable includes four influencing factors: first, GDP represents the economic growth level of hunan province; Second, the disposable income of rural residents and the consumption level of rural residents reflect the purchasing level of rural population. Third, poverty alleviation fund expenditure, support rural production and invest in agriculture, forestry, animal husbandry and fishery. It reflects the government's policy support for poverty alleviation. Fourth, total output value of agriculture, forestry, husbandry and fishery, total tourism revenue. It shows that poor areas themselves rely on the industrial structure to lift themselves out of poverty.

\section{THE EMPIRICAL ANALYSIS}

Multivariate large sample will no doubt provide abundant information for the research on poverty alleviation effect, but in most cases, because many variables may be relevant, increased the complexity of the problem analysis, to analysis at the same time bring inconvenience. If each index is analyzed separately, the analysis may be isolated and cannot be integrated. Blind reduction of indicators will lose a lot of information, easy to produce wrong conclusions. Therefore, it is necessary to find a reasonable method to reduce the loss of information contained in the original indicators while reducing the analysis indicators, and make a comprehensive analysis of the collected data. Because there is a certain correlation between each variable, it is possible to use fewer comprehensive indicators to synthesize all kinds of information existing in each variable and make the research easier.

TABLE I. KMO AND BARTLETT TESTS

\begin{tabular}{|l|c|c|}
\hline \multicolumn{2}{|c|}{ KMO sampling fitness } & .638 \\
\hline \multirow{2}{*}{ Bartlett's sphericity test } & chi-square & 254.374 \\
\cline { 2 - 3 } & Degrees of freedom & 28 \\
\cline { 2 - 3 } & significant & .000 \\
\hline
\end{tabular}

As can be seen from table 1 , KMO statistic $=0.638>0.5$, spherical test chi-square statistic $=254.374$, unilateral $\mathrm{p}=0.00<0.01$, suitable for factor analysis.

TABLE II. THE VARIANCE CONTRIBUTION RATE OF THE SAMPLE

\begin{tabular}{|c|r|r|r|r|r|r|}
\hline \multirow{2}{*}{$\begin{array}{c}\text { ingred } \\
\text { ient }\end{array}$} & total & The variance\% & $\begin{array}{c}\text { The } \\
\text { cumulative\% }\end{array}$ & total & $\begin{array}{c}\text { The } \\
\text { variance\% }\end{array}$ & $\begin{array}{c}\text { The } \\
\text { cumulative\% }\end{array}$ \\
\hline 1 & $\begin{array}{r}7.54 \\
2\end{array}$ & 94.280 & 94.280 & 7.542 & 94.280 & 94.280 \\
\hline 2 & .359 & 4.490 & 98.771 & & & \\
\hline 3 & .080 & 1.000 & 99.771 & & \\
\hline 4 & .012 & .150 & 99.922 & & & \\
\hline 5 & .003 & .039 & 99.961 & & & \\
\hline 6 & .002 & .027 & 99.988 & & \\
\hline 7 & .001 & .010 & 99.998 & & & \\
\hline 8 & .000 & .002 & 100.000 & & & \\
\hline \multicolumn{7}{|c|}{ Extraction method: principal component analysis. } \\
\hline
\end{tabular}

Table 2 use factor analysis to 8 variable, and can carry most of the variables effect factors are selected, when the factor of cumulative variance contribution rate reached $80 \%$, the default these factors can explain most of the factors, the factor to 1 of this article, the cumulative variance contribution rate of $94.28 \%$, that is, a factor to explain $94.28 \%$ of the variation of original variables. So choose a factor, and finally determine a principal component (REGR factor 1), named regional development index (E), the indexes including the regional economic growth, industrial development, rural residents' income, rural residents' consumption level, the government financial support, etc.

To examine the effect of hunan economic development on poverty reduction, selecting economic development index (E) and poverty rate $(\mathrm{P})$ do regression analysis, from the scatter 
diagram shows two variables approximate obey exponential distribution, the exponential regression model was constructed.

TABLE III. EXPONENTIAL MODEL RESULTS

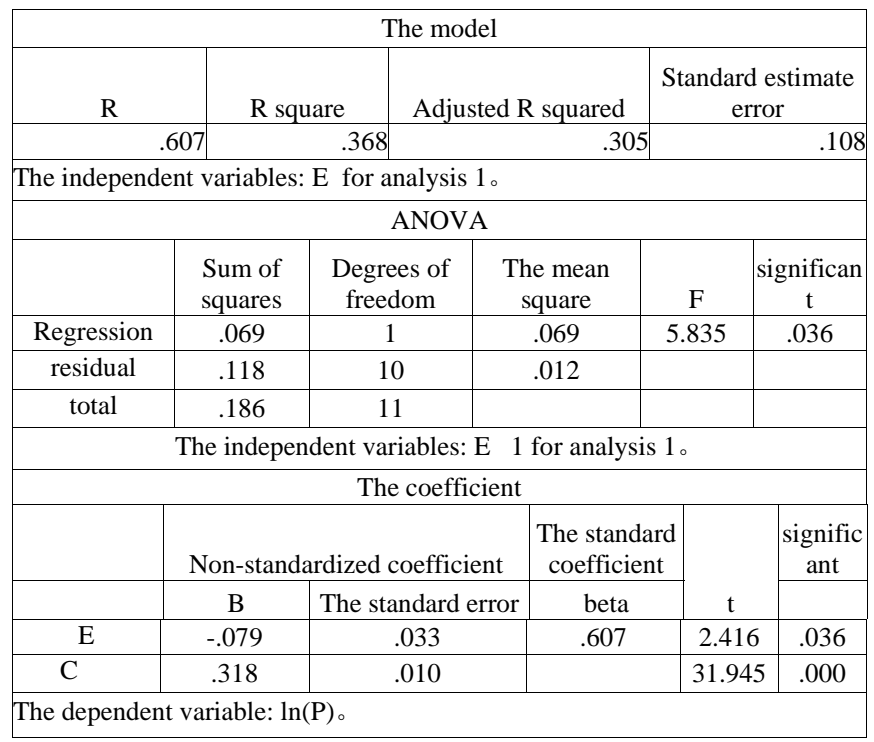

ANOVA is the result of variance analysis: the $\mathrm{F}$ value of the exponential model is 5.835 , and the $\mathrm{p}$ value is less than 0.05 , indicating that the regression equation has significant statistical significance. Regional economic development affects poverty reduction.

Exponential model $L N P=0.318 \times e^{-0.079 E}$ Poverty rate have negatively correlated with regional development level, development level of the region economic growth effected by government financial support, rural residents' income, rural residents' consumption level, the industry development. It has proved that regional development level plays an important role in rural poverty reduction.

\section{SUMMARY}

Using provincial data from 2005 to 2016, this paper selected the GDP, capital expenditures for poverty alleviation, supporting rural production, expenditure of rural residents' disposable income, rural residents' consumption level, agriculture, forestry and fishing, fishing output value of agriculture and forestry investment, tourism revenues on factor analysis of the eight variables extracted a factor on behalf of the regional development level, structure exponential model with development level index model and the incidence of poverty,

Doesn't directly affect economic growth out of poverty, but through income inequality status changes to affect poverty reduction, finance support agriculture alone cannot be helpful to the sustainability of poverty, finance support agriculture does not make sustainable poverty, in the use of the country's "blood transfusion" at the same time, should notice the function of "blood" of the poor areas themselves, through their own industry development to achieve out of poverty. Mostly in poor rural areas, agricultural development directly determines the rural residents income level, rely on the government, forestry and fishing investment and development of agriculture, forestry and fishing can increase rural residents' income, rural areas with the natural resources endowment can rely on tourism features business to develop the economy.

\section{REFERENCES}

[1] PARK A, WANG S. 2001. "”China's poverty statistics"”. China Economic Review, (12) : 384-398

[2] qin jianjun, wu laping. "'Research on the effect of rural poverty reduction on Financial support for agriculture ".2011 (3)

[3] hu shaoyu." Analysis on the impact of financial investment on China's rural anti-poverty effect “. Rural economy.2009 (4)

[4] zhang quanhong. "Empirical analysis of China's rural poverty alleviation fund investment and poverty reduction ". Economic review 2010(02)

[5] guo hongbao, qiu weijie. "The marginal decreasing trend and countermeasures of financial investment on rural poverty alleviation effect “.2005 (09)

[6] Wu yan.” Poverty reduction effect of China's rural financial development ". Journal of southwest university of nationalities. 2012(07)

[7] zhang fenghua, ye qisheng." Economic growth, industrial structure and rural poverty reduction”. Contemporary finance and economics. 2011(11)

[8] zhang fenghua, ye qisheng." Economic growth, industrial structure and rural poverty reduction “. Contemporary finance and economics.2011 (12) $: 14$ 